\title{
160 A PRECISION ATHLETIC TRACK MARKING SYSTEM
}

P Ravi kumar, ${ }^{1}$ C S P Rao, ${ }^{2}$ P C Reddy, ${ }^{3}$ Murali Krishna, ${ }^{4}$ Md Moiz ${ }^{1}$ Department of Physical Education, National Institute of Technology, Warangal, Andhra Pradesh, India; 'Department of Mechanical Engineering, National Institute of Technology, Warangal, Andhra Pradesh, India; ${ }^{3}$ President, NAPESS, Hyderabad, Andhra Pradesh, India; ${ }^{4}$ National Institute of Technology, Warangal, Andhra Pradesh, India

\subsection{6/bjsm.2010.078725.160}

Aim On an athletic track the marking of staggers is a time consuming activity. No accurate method for manual marking of stagger is available. The aim of this paper is to suggest simplified and accurate method for manual marking of stagger and relay change over zones and also the 'Mechatronic Track Marking System' device which is designed based on this is simple and reachable.

Methodology Staggers are required to be marked on imaginary lines known as running distance curve (RDC). Literature suggests use of large number of nails to be put on RDC so that the stretched tape follows RDC. This method is time consuming and inaccurate due to tape following a straight line between two nails. The improved method uses computer programme for converting curved staggers on RDC to chords on actual curved lines for straight marking by stretching the tape without use of any nails.

Results The method has been tested at JN Stadium, Warangal, (AP), India, NIT Stadium, Hanamkonda, Warangal, (AP), India and LB Stadium, Hyderabad (AP), India and found to be very accurate and time saving.

Conclusion Improved method and the devise is simple, less time consuming, accurate and recommended to be adopted for teaching and professional use. 